\title{
Review Article \\ The Significance of Long Noncoding RNA H19 in Predicting Progression and Metastasis of Cancers: A Meta-Analysis
}

\author{
Wei Jing, ${ }^{1}$ Man Zhu, ${ }^{1}$ Xian-wei Zhang, ${ }^{1}$ Zhong-ya Pan, ${ }^{1}$ Shan-shan Gao, ${ }^{1}$ Hu Zhou, \\ Shi-li Qiu, ${ }^{1}$ Chun-zi Liang, ${ }^{1}$ and Jian-cheng Tu ${ }^{1,2}$ \\ ${ }^{1}$ Department of Laboratory Medicine, Clinical Laboratory Medicine and Center for Gene Diagnosis, \\ Zhongnan Hospital of Wuhan University, Wuhan 430071, China \\ ${ }^{2}$ School of Laboratory Medicine, Hubei University of Traditional Chinese Medicine, Wuhan 430071, China \\ Correspondence should be addressed to Jian-cheng Tu; jianchengtu@whu.edu.cn
}

Received 27 May 2016; Revised 31 July 2016; Accepted 15 August 2016

Academic Editor: Lei Yao

Copyright (C) 2016 Wei Jing et al. This is an open access article distributed under the Creative Commons Attribution License, which permits unrestricted use, distribution, and reproduction in any medium, provided the original work is properly cited.

\begin{abstract}
Recently, numerous studies indicate that H19 plays a key role in tumorigenesis, but the results have been disputed, especially in the aspects of tumor progression and metastasis. Therefore, we performed this meta-analysis to systematically summarize the relationship between H19 and cancers. We searched PubMed, the Cochrane Library, CNKI, and Chinese Wan Fang to identify eligible studies. Odds ratios and 95\% confidence intervals were calculated to assess the effect size. A total of 13 studies were enrolled in this meta-analysis, which was performed by Revman5.3 and Statall.0 software. Our meta-analysis showed that the expression of $\mathrm{H} 19$ was associated with distant metastasis in nongastrointestinal tumors $(\mathrm{OR}=3.85,95 \% \mathrm{CI}=1.31-11.36, P=0.01)$ and, in gastrointestinal tumors $(\mathrm{OR}=0.34,95 \% \mathrm{CI}=0.15-0.78, P=0.01)$, lymph node metastasis $(\mathrm{OR}=2.04,95 \% \mathrm{CI}=1.19-3.48$, $P=0.009)$. Moreover, in gastric cancer, $\mathrm{H} 19$ expression was significantly related to histological grade $(\mathrm{OR}=0.50,95 \% \mathrm{CI}=0.29-$ $0.86, P=0.01)$, TNM stage $(\mathrm{OR}=0.19,95 \% \mathrm{CI}=0.11-0.33, P<0.01)$, and tumor invasion depth $(\mathrm{OR}=0.11,95 \% \mathrm{CI}=0.04-0.27$, $P<0.01)$. Therefore, $\mathrm{H} 19$ could serve as a potential marker for progression and metastasis evaluation of cancers.
\end{abstract}

\section{Introduction}

Cancers have the highest mortality in the world. In the year 2008 worldwide, 7.6 million people died of cancers; meanwhile 12.4 million new cases were suffering from cancers. It is forecasted that the deaths from cancers will increase to 13.1 million in 2030 [1]. The treatment of cancers can cause side effects in patients' physical and mental conditions, including pain, vomiting, fatigue, anepithymia, and body weight change [2]. Although patients can be successfully treated by surgery, chemotherapy, and interventional therapy, cancers may recur and be diagnosed in the advanced stage after the related symptoms appear and the 5-year survival rate is relatively low [3]. Unknowing the mechanisms of tumorigenesis is due to poor therapy and a high probability of relapse after treatment [4]. Recently, researchers focus on the biological markers associated with progression and metastasis in cancers. Therefore, identifying reliably diagnostic markers for cancers is urgently needed.
Noncoding RNAs are classified into small noncoding RNAs (miRNA) and long noncoding RNAs (lncRNAs) according to the transcript size. LncRNAs are defined as noncoding RNAs longer than 200 nucleotides with no proteincoding capacity [5]. Khachane and Harrison [6] demonstrated that the proportion of the lncRNA associated with cancer was 2 times higher than that of the protein-coding genes which have reference to cancer in the human genome. Increasing evidences have pointed to a relationship between lncRNAs and cancers, including metastasis, migration, and apoptosis, which change the original concept that lncRNA genes were just "noise" [7]. For example, urothelial carcinoma-associated 1 (UCA1) can directly bind to miR-216b, and the abnormal expression of UCA1 in HCC is correlated with tumor-node-metastasis (TNM) stage and metastasis [8]. In breast cancer, the overexpression of the plasmacytoma variant translocation 1 gene (PVT1) could inhibit the apoptosis of tumor cells, which is involved in the pathophysiology of 
breast cancer [9]. Recently, researches indicated that many lncRNAs played important roles in cancers.

LncRNA H19, which is the first discovered lncRNA by Brannan, is a paternally imprinted gene located close to the telomeric region of chromosome 11p15.5, which is frequently involved in tumors $[10,11]$. Matouk et al. [12] indicated that $\mathrm{H} 19$ was not expressed in tissues after birth and reexpressed in the tumor tissues. $\mathrm{H} 19$ is associated with the tumorigenesis and invasion, partially via the regulation of carcinogenic miRNA-675 which locates in its first exon [13]. BarsyteLovejoy et al. [14] showed that c-myc can induce the expression of $\mathrm{H} 19$ and when acetylation occurred in its promoter region, transcription initiated. H19 was upregulated in several different tumors, including esophageal cancer, gastric cancer, and breast cancer [15-17]. Numbers of researches about H19 were done to explore the mechanism in cancers. Therefore, we conducted a meta-analysis to evaluate the value of H19 with tumor metastasis and progression in a larger sample size of patients.

\section{Materials and Methods}

2.1. Publication Search. To obtain relevant articles for this meta-analysis, we searched the databases PubMed, Cochrane library, CNKI, and Chinese Wan Fang for studies published up to July 2016. Both medical subject heading terms and freetext words were used in the databases to increase sensitivity. The following search keywords were used: "H19 and cancer," "progression and metastasis," "long noncoding RNA H19." Meanwhile, we examined all articles in these eligible studies to identify additional relevant literature that had not been retrieved from the databases.

2.2. Inclusion and Exclusion Criteria. Eligible studies in this meta-analysis had to meet the following standards: patients in the study were diagnosed with cancers; researches were association between $\mathrm{H} 19$ and cancer; sufficient published data were provided to calculate odds ratios (ORs) and 95\% confidence interval (95\% CI). If there were duplicated data, we chose the most complete data or the most recent one. Exclusion criteria were as follows: studies without usable data, case reports, reviews, letters, and conference abstracts.

2.3. Data Extraction. Two investigators extracted relevant data from the eligible studies independently, including the first author, year of publication, country, tumor type, sample, sample size, and cut-off value.

2.4. Statistical Analysis. ORs and 95\% CIs were used to assess the association between $\mathrm{H} 19$ and clinic features in cancers. The features included gender, lymph node status, and distant metastasis. Meanwhile, histological grade, TNM stage, and tumor invasion depth were extracted from the articles about gastric cancer. The clinicopathological factor of gender was divided into males and females. As for lymph node status (LNM) and distant metastasis (DM), we separated them into positive and negative. Similarly, histological grade included low-grade and high/middle-grade, respectively. According to the American Joint Committee on Cancer (AJCC) staging system [18], TNM stage was separated into two parts, which were early stage $(\leq \mathrm{II})$ and late stage $(\geq \mathrm{III})$. The tumor invasion depth was divided into T0-T1 and T2 or above. We used Revman5.3 software (Revman, the Cochrane Collaboration) to perform the meta-analysis and evaluate heterogeneity between studies by Cochrane $Q$-test and $P$ values. If heterogeneity was present $\left(I^{2} \geq 50 \%\right.$ or $\left.P \leq 0.05\right)$, random-effect model was used to calculate pooled ORs. If not, the fixedeffect model was more appropriate $[19,20]$. The Stata11.0 software (Stata, College Station) was performed to evaluate the sensitivity and publication bias of the studies. Publication bias was evaluated by Begg's test; $P<0.05$ was considered statistically significant.

\section{Results}

3.1. Characteristics of Included Studies. As shown in the flow diagram (Figure 1), we searched 392 articles in the databases. After screening the titles and abstracts, 351 of records were removed. Then because of no usable data, 28 papers were excluded. As a result, a total of 13 articles were included in the current meta-analysis [3, 11, 21-31].

Table 1 summarized the main characteristics of the included 13 studies ranging from 2005 to 2016. Among these 13 studies, 11 were from China, 1 from Japan, and 1 from Brazil. Specimens were divided into 8 types: 4 gastric cancer (GC) $[3,22,24,27]$; 1 non-small-cell lung cancer (NSCLC) [21], 1 renal cell carcinoma (RCC) [11], 2 gallbladder cancer (GBC) $[23,30], 1$ head-and-neck squamous cell carcinomas (HNSCC) [25], 2 esophageal cancer (EC) [26, 29], 1 ovarian cancer (OC) [28], and 1 colorectal cancer (CRC) [31]. Sample types included tissues and plasma. 13 studies enrolling 872 participants were with a maximum sample size of 133 and a minimum sample size of 20 patients. Because of variations in the cut-off definitions, the cut-off values were different in these studies.

\subsection{Association between H19 and Clinicopathological Param-} eters. A total of 802 patients enrolled in 12 studies reported that the expression levels of H19 were related to gender. Analysis showed that the expression levels of H19 were not associated with the gender of patients $(\mathrm{OR}=0.94,95 \% \mathrm{CI}=$ $0.70-1.26, P=0.68$, fixed-effect) (Figure 2(a)). Five studies showed the relationship between $\mathrm{H} 19$ and distant metastasis. Due to the different types of cancers, we divided cancers into gastrointestinal tumors and nongastrointestinal tumors. Then we performed subgroup analysis. Result by cancer type indicated that H19 expression was significantly related to distant metastasis in nongastrointestinal tumors $(\mathrm{OR}=3.85$, 95\% CI $=1.31-11.36, P=0.01$, random-effect) and also in the gastrointestinal tumors $(\mathrm{OR}=0.34,95 \% \mathrm{CI}=0.15-0.78$, $P=0.01$, random-effect). However, we found that there was no correlation between $\mathrm{H} 19$ and these two types of cancers (nongastrointestinal and gastrointestinal cancers) $(\mathrm{OR}=1.03$, 95\% CI $=0.29-3.69, P=0.96$, random-effect) (Figure 2(b)). Finally, we analyzed the association between $\mathrm{H} 19$ and lymph node metastasis, and the result elaborated that lymph node metastasis occurred with the expression levels of H19 


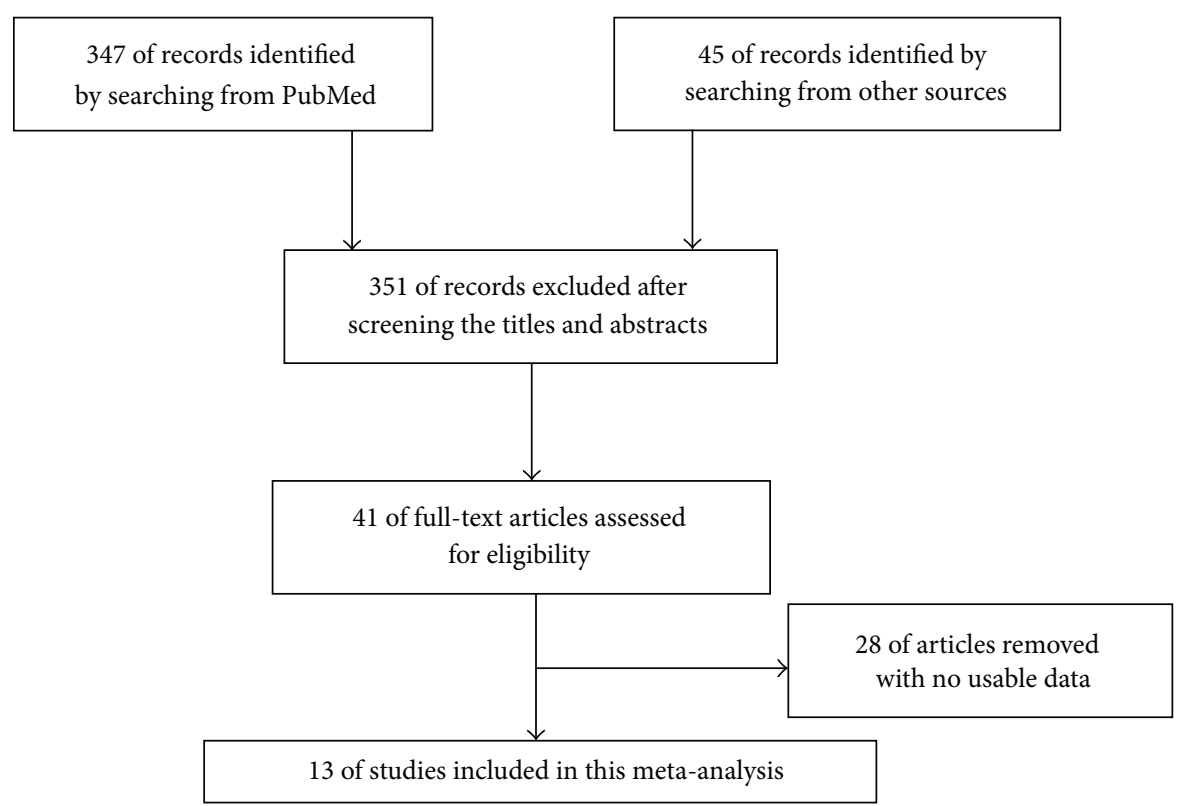

FIGURE 1: The flow diagram of this meta-analysis.

TABLE 1: Characteristics of studies included in this meta-analysis for H19.

\begin{tabular}{|c|c|c|c|c|c|c|}
\hline Author & Year & Country & Tumor type & Sample & Sample size & Cut-off value \\
\hline Zhang [3] & 2014 & China & $\mathrm{GC}$ & Tissue & 80 & Mean \\
\hline Zhang [21] & 2016 & China & NSCLC & Tissue & 70 & Median \\
\hline Arita [22] & 2013 & Japan & GC & Plasma & 43 & 0.32 \\
\hline Wang [11] & 2015 & China & RCC & Tissue & 92 & 3.8-fold change \\
\hline Wang [23] & 2016 & China & GBC & Tissue & 20 & NA \\
\hline You [24] & 2014 & China & GC & Tissue & 30 & Median \\
\hline Esteves [25] & 2005 & Brazil & HNSCC & Tissue & 35 & Absence/presence \\
\hline Huang [26] & 2015 & China & EC & Tissue & 133 & Median \\
\hline Chen [27] & 2016 & China & GC & Tissue & 128 & Median \\
\hline Zhu [28] & 2015 & China & OC & Tissue & 70 & NA \\
\hline Tan [29] & 2016 & China & EC & Tissue & 64 & NA \\
\hline Wang [30] & 2016 & China & GBC & Tissue & 24 & Median \\
\hline Han [31] & 2016 & China & CRC & Tissue & 83 & 3.8-fold change \\
\hline
\end{tabular}

GC: gastric cancer, NSCLC: non-small-cell lung cancer, RCC: renal cell carcinoma, GBC: gallbladder cancer, HNSCC: head-and-neck squamous cell carcinomas, EC: esophageal cancer, OC: ovarian cancer, and CRC: colorectal cancer.

$(\mathrm{OR}=2.04,95 \% \mathrm{CI}=1.19-3.48, P=0.009$, random-effect $)$

(Figure 2(c)).

\subsection{Association between H19 and Clinicopathological Param-} eters in GC. Four of the 13 studies enrolling 281 patients indicated that $\mathrm{H} 19$ expression was related to the clinicopathological characteristics in GC $[3,22,24,27]$. In those studies, H19 expression was significantly associated with histological grade $(\mathrm{OR}=0.50,95 \% \mathrm{CI}=0.29-0.86, P=0.01$, fixed-effect $)$, TNM stage $(\mathrm{OR}=0.19,95 \% \mathrm{CI}=0.11-0.33, P<0.00001$, fixed-effect), and tumor invasion depth (OR $=0.11,95 \% \mathrm{CI}$ $=0.04-0.27, P<0.00001$, fixed-effect) (Figures 3(a)-3(c)) in GC.

3.4. Publication Bias and Sensitivity Analysis. We used Begg's test to evaluate the publication bias, respectively (Figures $4(\mathrm{a})-4(\mathrm{f}))$. In our meta-analysis, Begg's test indicated that there was no publication bias in all subgroups and all the values of $P>0.05$. Sensitivity analysis was performed by Stata11.0 software to assess whether the individual study affected the overall results. The results suggested that individual study had little influence on our final results (Figures 5(a)-5(f)), which demonstrated that our results were relatively stable and credible.

\section{Discussion}

The occurrence of cancers is a multifactor, multistep, and complex process. Due to the lack of early prediction index, numerous patients were diagnosed in their late stage. In recent years, lncRNA plays increasingly important roles in epigenetics, pretranscription, and posttranscription, which is also becoming a research hotspot [32]. However, only a few diverse hypothetical mechanisms were presented by 


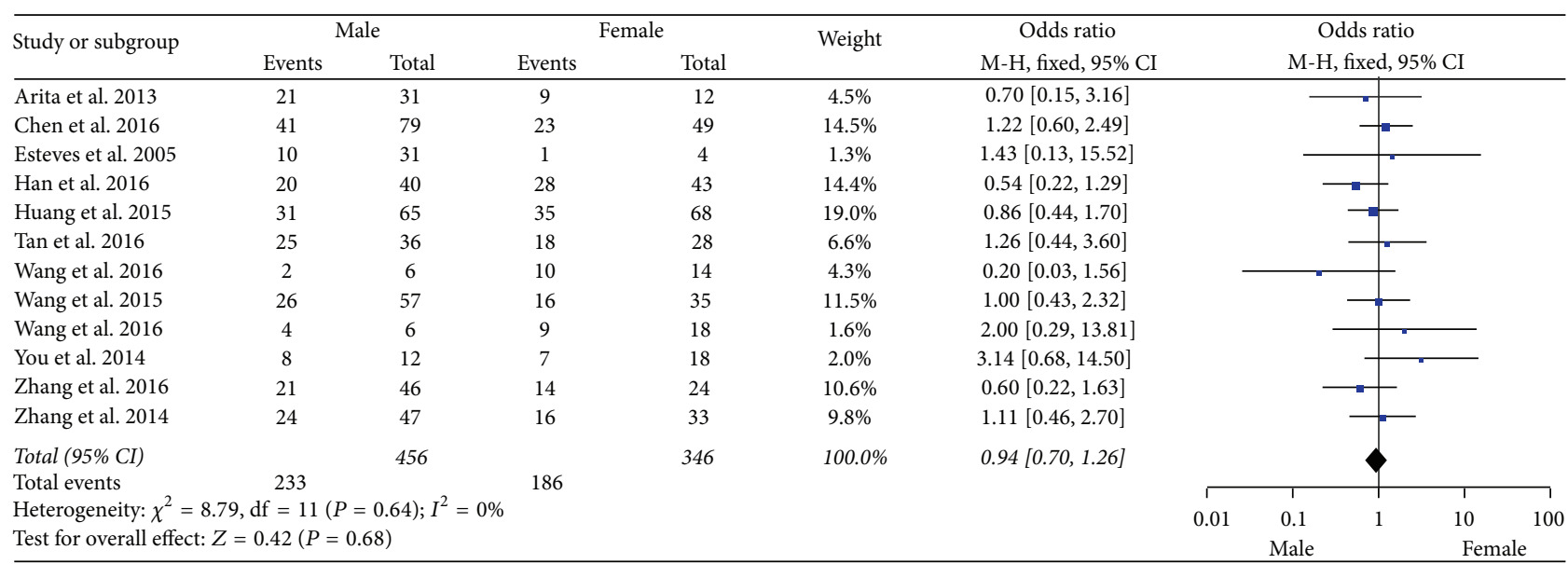

(a)

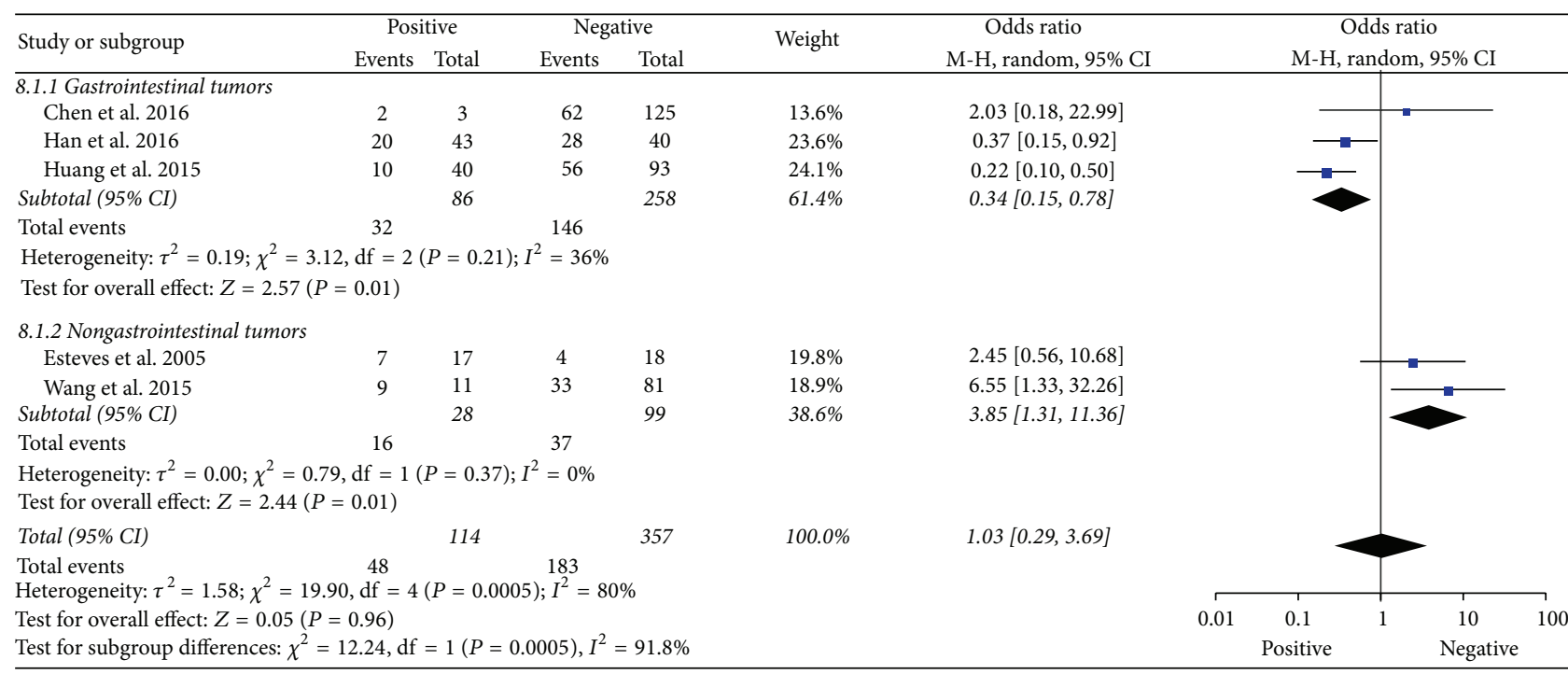

(b)

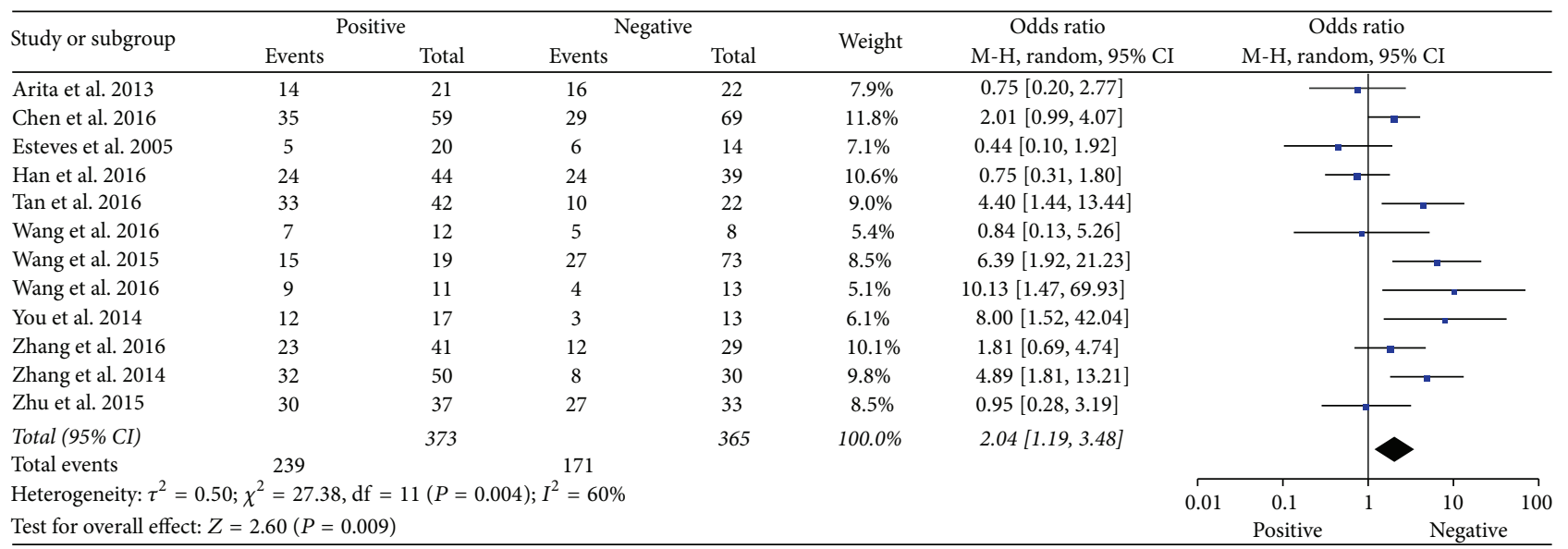

(c)

FIGURE 2: Forest plot for the association between H19 expression levels with clinical parameters in cancers. (a) Gender. (b) Distant metastasis. (c) Lymph node metastasis. 


\begin{tabular}{|c|c|c|c|c|c|c|c|c|c|c|}
\hline \multirow{3}{*}{$\begin{array}{l}\text { Study or subgroup } \\
\text { Chen et al. } 2016\end{array}$} & \multicolumn{2}{|c|}{ Middle/high } & \multicolumn{2}{|c|}{ Low } & \multirow{2}{*}{ Weight } & \multirow{2}{*}{$\begin{array}{c}\text { Odds ratio } \\
\text { M-H, fixed, 95\% CI }\end{array}$} & \multirow{2}{*}{\multicolumn{4}{|c|}{$\begin{array}{c}\text { Odds ratio } \\
\text { M-H, fixed, 95\% CI }\end{array}$}} \\
\hline & \multirow{2}{*}{$\frac{\text { Events }}{27}$} & \multirow{2}{*}{$\frac{\text { Total }}{64}$} & \multirow{2}{*}{$\frac{\text { Events }}{37}$} & \multirow{2}{*}{$\begin{array}{c}\text { Total } \\
64\end{array}$} & & & & & & \\
\hline & & & & & $56.2 \%$ & $0.53[0.26,1.07]$ & & & & \\
\hline You et al. 2014 & 5 & 12 & 10 & 18 & $12.3 \%$ & $0.57[0.13,2.50]$ & & - & & \\
\hline Zhang et al. 2014 & 8 & 23 & 32 & 57 & $31.5 \%$ & $0.42[0.15,1.14]$ & & & & \\
\hline Total (95\% CI) & & 99 & & 139 & $100.0 \%$ & $0.50[0.29,0.86]$ & & & & \\
\hline $\begin{array}{l}\text { Total events } \\
\text { Heterogeneity } \cdot \gamma^{2}=\end{array}$ & 40 & 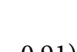 & 79 & & & & & & & \\
\hline $\begin{array}{l}\text { Heterogeneity: } \chi^{2}= \\
\text { Test for overall effec }\end{array}$ & $\begin{array}{l}\text { ff }=2(P \\
2.53(P=\end{array}$ & $\begin{array}{l}=0.91) \\
0.01)\end{array}$ & $=0 \%$ & & & & 0.01 & $\begin{array}{c}0.1 \\
\text { Middle/high }\end{array}$ & $\begin{array}{l}1 \\
10 \\
\text { Low }\end{array}$ & 100 \\
\hline
\end{tabular}

(a)

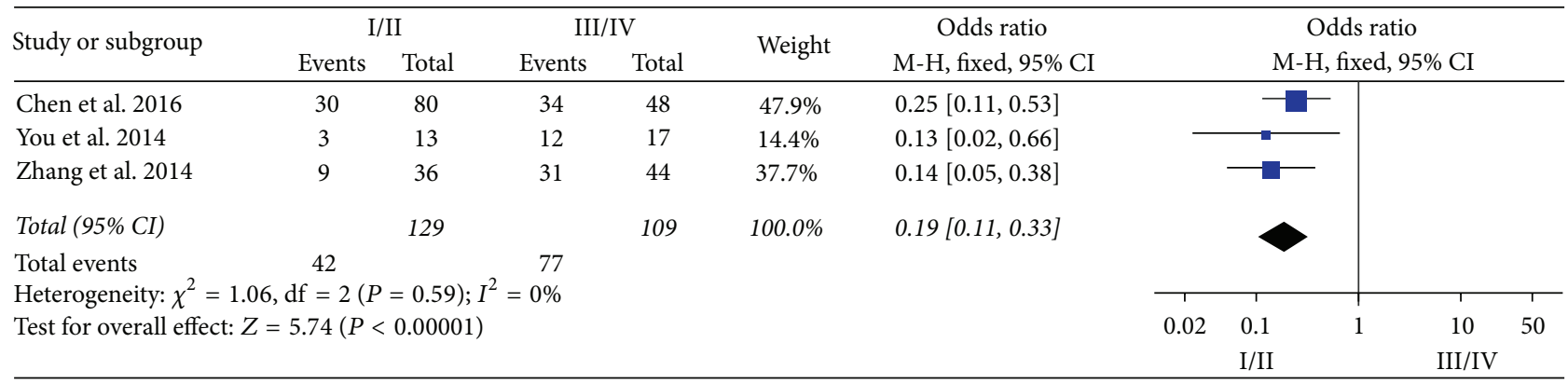

(b)

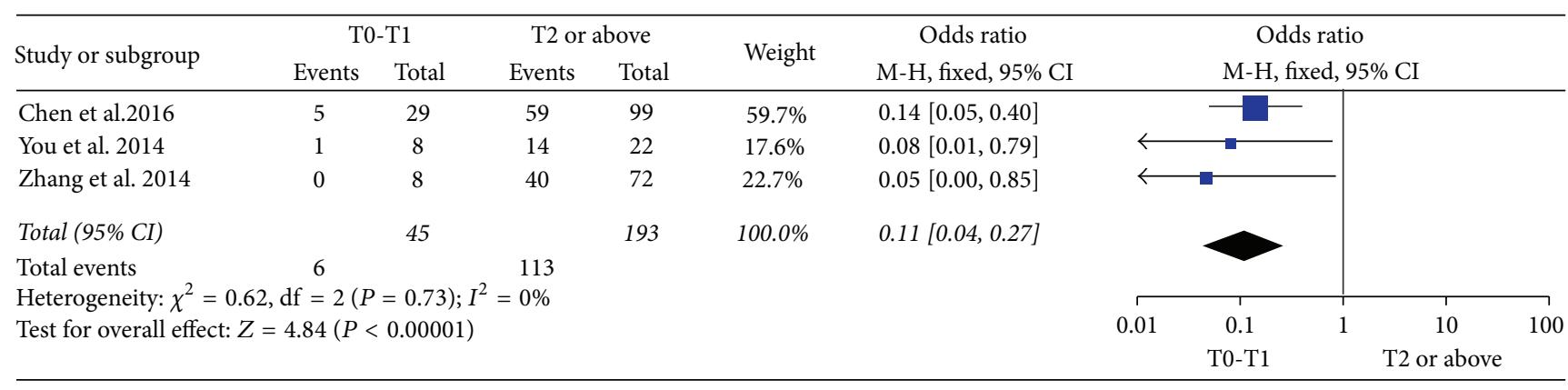

(c)

FIGURE 3: Forest plot for the association between H19 expression levels with clinical parameters in GC. (a) Histological grade in GC. (b) TNM in GC. (c) Tumor invasion depth in GC.

which the lncRNAs could exert their effects: interfering in the expression of the adjacent encoding protein gene [33]; participating in transcription and chromatin-modifying and DNA methyltransferases to specific genomic [34]; binding with functional protein [35]; being the precursors of miRNAs and affecting targets gene of miRNA $[36,37]$; regulating signaling pathway via combining with chromosome [38, 39].

$\mathrm{H} 19$ is one of the cancer-related lncRNAs, which has an oncogenic function and is strongly expressed in cancers, such as colorectal cancer, osteosarcoma, and bladder cancer [40-42]. In 2013, Luo et al. [43] demonstrated that H19 was remarkably increased in bladder cancer tissues, comparing with adjacent normal control tissues, and promoted bladder cancer cells proliferation in vitro. Vennin et al. [44] elaborated that H19/miR-675 enhanced the cell proliferation and migration in vitro and increased tumor growth and metastasis in vivo. Meanwhile, H19 decreased ubiquitin ligase E3 family
(c-Cbl and Cbl-b) which suppressed tumorigenesis through its microRNA. Thus, H19 could be considered as a potential prognostic factor for various cancers.

The important reason for the low 5-year survival rate is the occurrence of distant metastasis and lymph node metastasis. Recently, researchers indicated that H19 inhibited endogenous let-7 function, causing derepression of HMGA2 which could mediate epithelial-mesenchymal transition (EMT) in pancreatic ductal adenocarcinoma (PDAC), and contributed to PDAC metastasis [45]. Raveh et al. [46] indicated that $\mathrm{H} 19$ played an important role in EMT process, which showed that $\mathrm{H} 19$ exerted a metastatic function in cancers. P53 is known as a tumor suppressor gene and arrests tumor growth and metastasis [47]. In 2012, Yang et al. [48] found that $\mathrm{H} 19$ was associated with p53 and this association led to partial p53 inactivation. Also, in bladder cancer cells, H19 positively regulated miR-675 expression, which could 


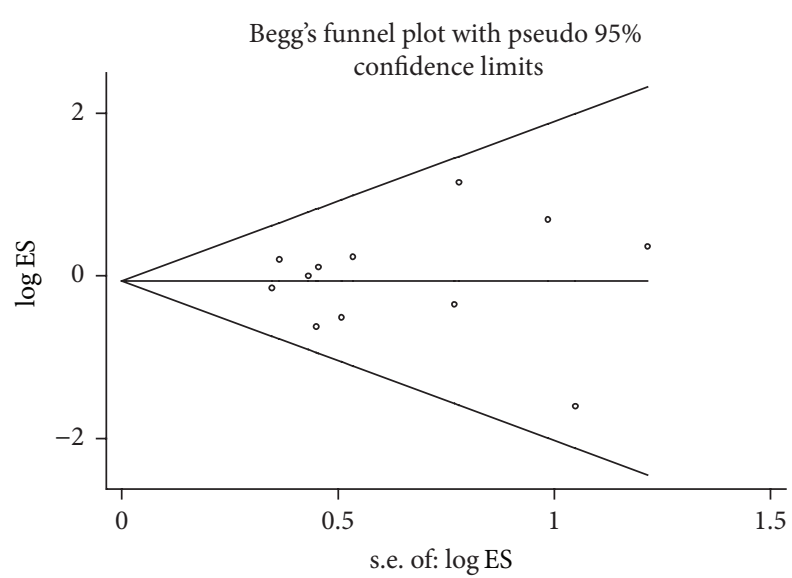

(a)

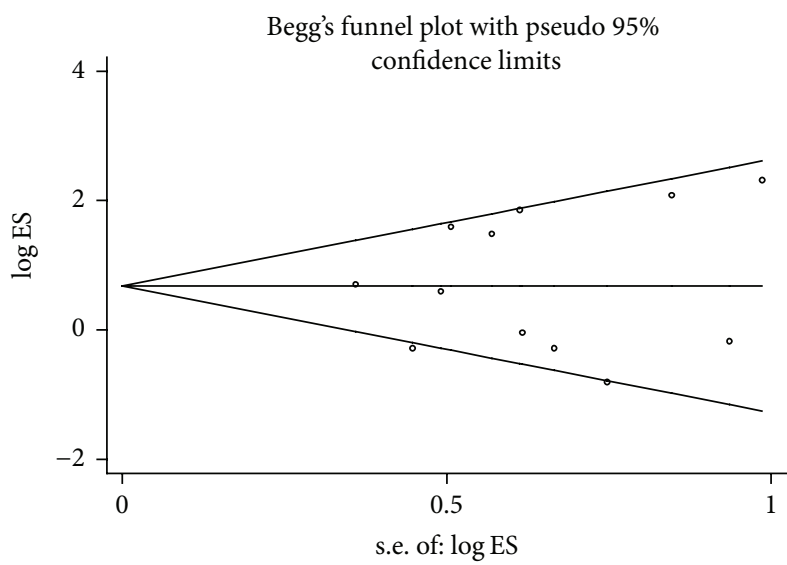

(c)

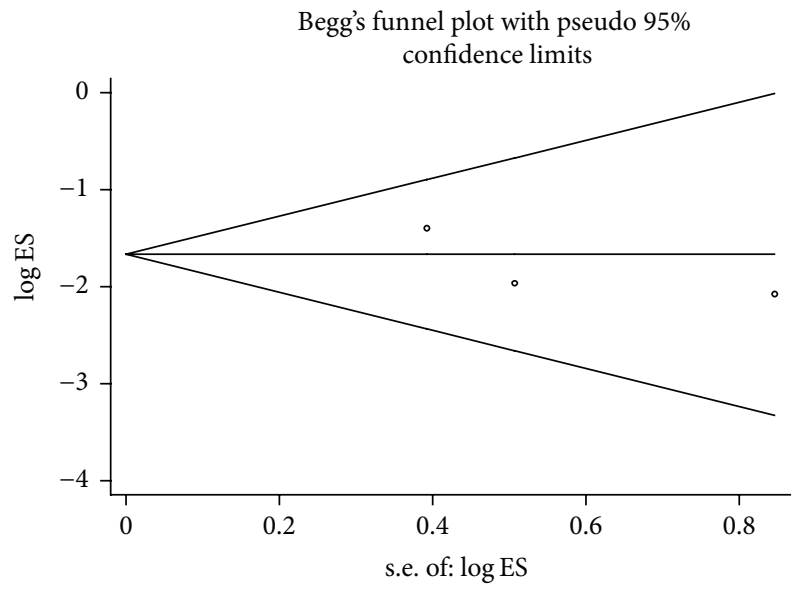

(e)

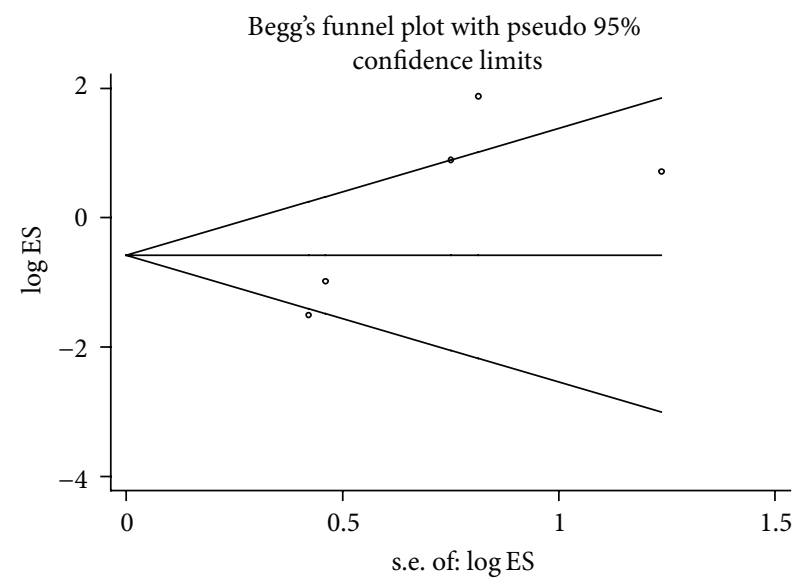

(b)

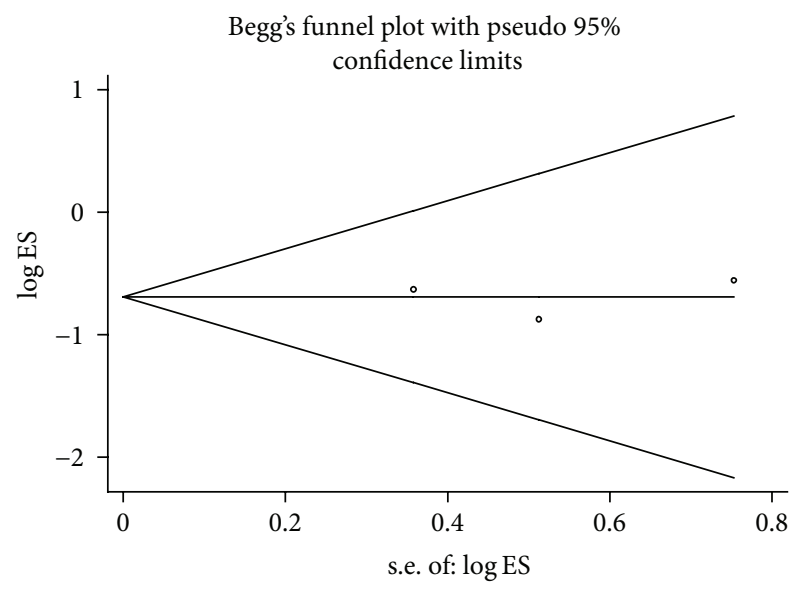

(d)

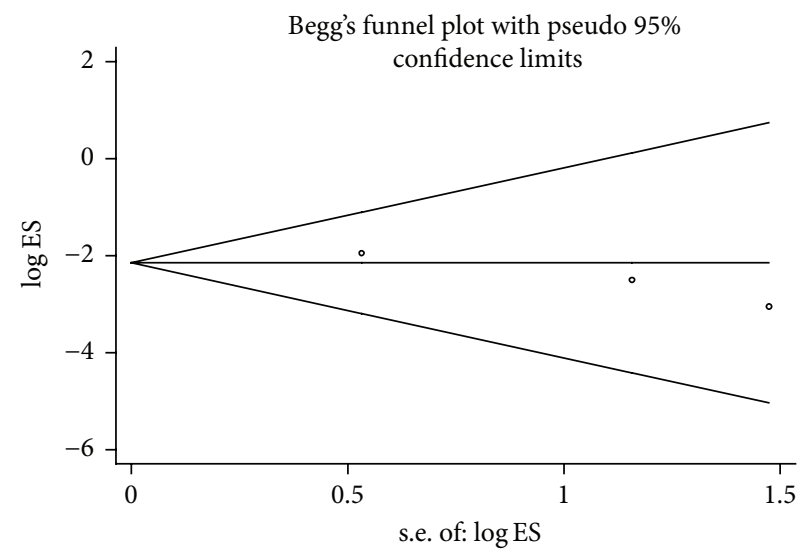

(f)

FIgURE 4: Begg's test for publication bias. (a) Gender. (b) Distant metastasis. (c) Lymph node metastasis. (d) Histological grade in GC. (e) TNM in GC. (f) Tumor invasion depth in GC.

inhibit p53 activation [49]. Therefore, H19 could be used to predict the occurrence of metastasis in cancers. In this metaanalysis, we found that high levels of $\mathrm{H} 19$ were more prone to lead to lymph node metastasis $(\mathrm{OR}=2.04,95 \% \mathrm{CI}=1.19-3.48$,
$P=0.009$ ). Furthermore, the level of H19 expression in DMpositive group was 3.85 -fold higher than in the DM-negative group in nongastrointestinal tumors $(\mathrm{OR}=3.85,95 \% \mathrm{CI}=$ 1.31-11.36, $P=0.01)$. However, in gastrointestinal tumors, 


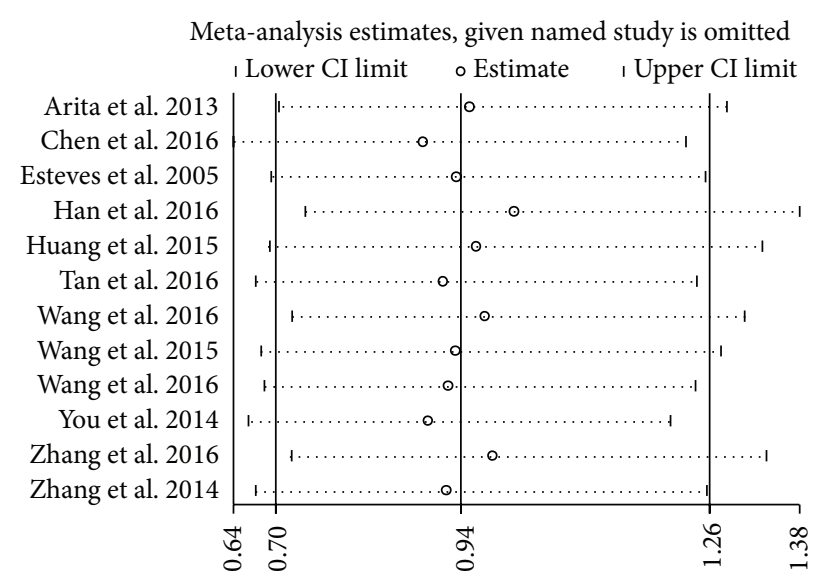

(a)

Meta-analysis estimates, given named study is omitted

\begin{tabular}{|c|c|c|c|}
\hline \multicolumn{2}{|c|}{ I Lower CI limit } & \multicolumn{2}{|c|}{ I Upper CI limit } \\
\hline Arita et al. 2013 & $\mid \not \ldots \ldots \ldots \ldots \ldots$ & $\ldots \circ \ldots \ldots$ & $\ldots \ldots \ldots 1$ \\
\hline Chen et al. 2016 & & & $\cdots \cdots+1$ \\
\hline Esteves et al. 2005 & & $\cdots \cdot \bullet$ & $\cdots \cdots 1$ \\
\hline Han et al. 2016 & 1. & $\ldots .0$. & . \\
\hline Tan et al. 2016 & $\cdots \cdots$ & $\ldots \ldots$. & \\
\hline Wang et al. 2016 & & &. .1 \\
\hline Wang et al. 2015 & $\cdots 0$. & (n, & \\
\hline Wang et al. 2016 & $\cdots o$. & & \\
\hline You et al. 2014 & & & \\
\hline Zhang et al. 2016 & & o..... &. .1 \\
\hline Zhang et al. 2014 & ..... & $\ldots \ldots \ldots \ldots \ldots \ldots \ldots, 1$ & \\
\hline Zhu et al. 2015 & $1 \ldots$. & . $.0 \ldots \ldots \ldots \ldots \ldots \ldots \ldots \ldots$ & $\cdots \cdots 1$ \\
\hline
\end{tabular}

(c)

Meta-analysis estimates, given named study is omitted I Lower CI limit o Estimate । Upper CI limit

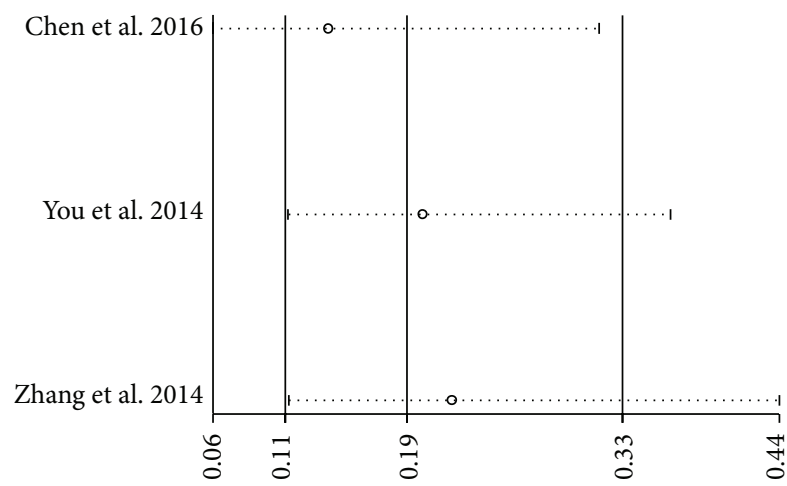

(e)
Meta-analysis estimates, given named study is omitted । Lower CI limit oEstimate ,Upper CI limit

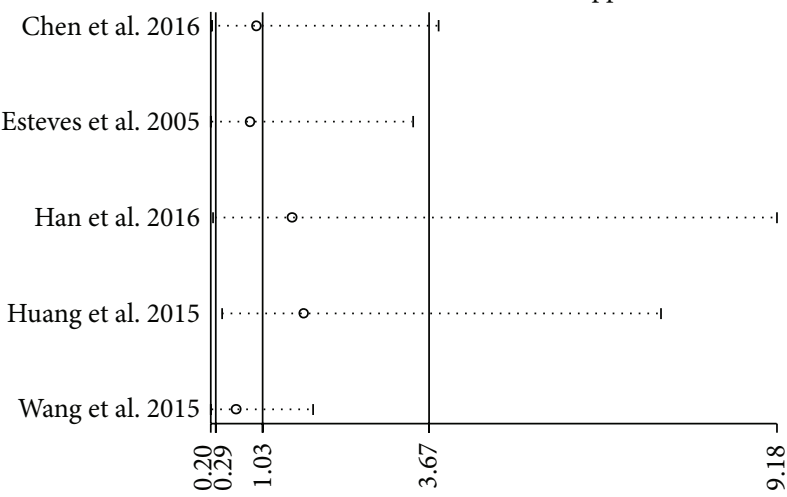

(b)

Meta-analysis estimates, given named study is omitted I Lower CI limit o Estimate I Upper CI limit

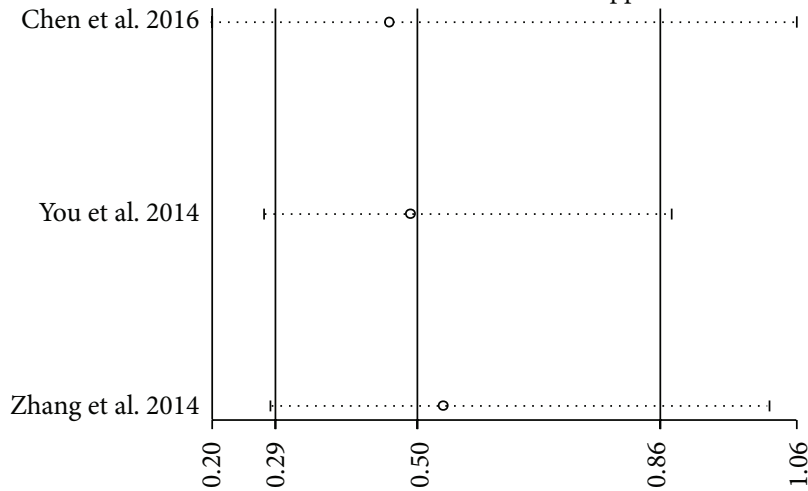

(d)

Meta-analysis estimates, given named study is omitted I Lower CI limit o Estimate । Upper CI limit

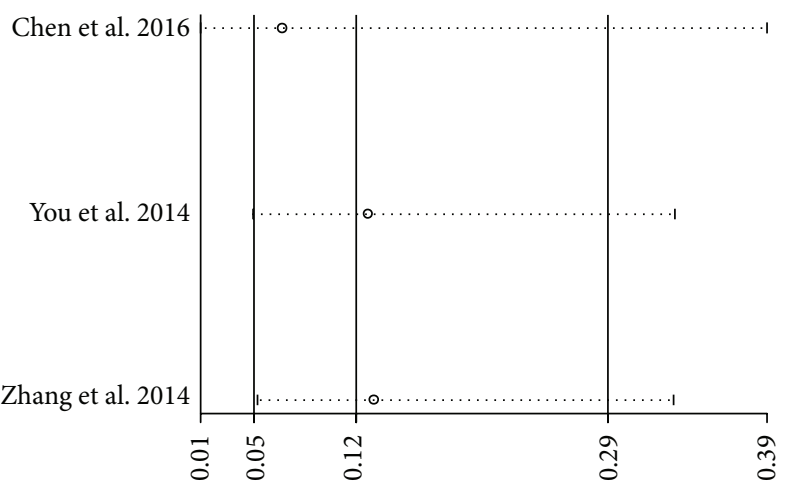

(f)

Figure 5: Sensitivity analyses of the studies. (a) Gender. (b) Distant metastasis. (c) Lymph node metastasis. (d) Histological grade in GC. (e) TNM in GC. (f) Tumor invasion depth in GC.

our result showed that the expression of H19 in DM-negative group was 2.94-fold higher than in the DM-positive group $(\mathrm{OR}=0.34,95 \% \mathrm{CI}=0.15-0.78, P=0.01)$; insufficient sample size was the possible reason for the different results in various cancers. Therefore, further studies should be done with larger sample sizes.
In subgroups analysis, we found that the levels of $\mathrm{H} 19$ were significantly related to the histological grade $(\mathrm{OR}=0.50$, $95 \% \mathrm{CI}=0.29-0.86, P=0.01)$, TNM stage $(\mathrm{OR}=0.19$, $95 \% \mathrm{CI}=0.11-0.33, P<0.01)$, and tumor invasion depth $(\mathrm{OR}=0.11,95 \% \mathrm{CI}=0.04-0.27, P<0.01)$ in GC. Previous study demonstrated that $\mathrm{H} 19$ was an important factor in GC 
tumorigenesis and metastasis by interacting with its target gene ISM1 that had a dual function in endothelial cell survival and cell death [16]. In included studies, Chen et al. [27] found that knockdown of H19 could inhibit GC cell migration and invasion partly via regulating E-cadherin protein expression which can decrease the occurrence of invasiveness. Therefore, H19 can serve as a sentinel, indicating the development of GC. However, the relationship between H19 expression and other cancers might need more studies to illuminate.

It should be stressed that there were limitations in our analysis. Most studies reported positive results, but those with negative results are generally less likely to be published. In addition, there were insufficient data to fully confirm the association between $\mathrm{H} 19$ and clinicopathological characteristics, which needs more studies. Finally, the limited number of studies may affect the results of subgroups.

\section{Conclusions}

In conclusion, this meta-analysis suggested that H19 might predict progression and metastasis in cancers. We firstly explored the correlation of H19 expression levels with lymph node metastasis and distant metastasis in cancers. Meanwhile, the expression of $\mathrm{H} 19$ was associated with histological grade, TNM, and tumor invasion depth in GC. Therefore, our study demonstrated that $\mathrm{H} 19$ might be a predictive factor for assessing progression and metastasis in cancers.

\section{Competing Interests}

The authors declare no conflict of interests.

\section{Acknowledgments}

This study was supported by the National Basic Research Program of China (973 Program) (2012CB720605).

\section{References}

[1] K. Schmidt and I. Podmore, "Current challenges in volatile organic compounds analysis as potential biomarkers of cancer," Journal of Biomarkers, vol. 2015, Article ID 981458, 16 pages, 2015.

[2] K. Wesley and P. Fizur, "A review of mobile applications to help adolescent and young adult cancer patients," Adolescent Health, Medicine and Therapeutics, vol. 2015, article 6, pp. 141-148, 2015.

[3] E.-B. Zhang, L. Han, D.-D. Yin, R. Kong, W. De, and J. Chen, "c-Myc-induced, long, noncoding H19 affects cell proliferation and predicts a poor prognosis in patients with gastric cancer," Medical Oncology, vol. 31, article 914, 2014.

[4] T.-T. Fang, X.-J. Sun, J. Chen et al., "Long non-coding RNAs are differentially expressed in hepatocellular carcinoma cell lines with differing metastatic potential," Asian Pacific Journal of Cancer Prevention, vol. 15, no. 23, pp. 10513-10524, 2014.

[5] L. Han, P. Ma, S.-M. Liu, and X. Zhou, "Circulating long noncoding RNA GAS5 as a potential biomarker in breast cancer for assessing the surgical effects," Tumor Biology, vol. 37, pp. 68476854, 2016.
[6] A. N. Khachane and P. M. Harrison, "Mining mammalian transcript data for functional long non-coding RNAs," PLoS ONE, vol. 5, no. 4, Article ID e10316, 2010.

[7] G. Lavorgna, R. Vago, M. Sarmini, F. Montorsi, A. Salonia, and M. Bellone, "Long non-coding RNAs as novel therapeutic targets in cancer," Pharmacological Research, vol. 110, pp. 131138, 2016.

[8] W. Jing, S. Gao, M. Zhu et al., "Potential diagnostic value of lncRNA SPRY4-IT1 in hepatocellular carcinoma," Oncology Reports, vol. 36, pp. 1085-1092, 2016.

[9] Y. Guan, W.-L. Kuo, J. L. Stilwell et al., "Amplification of PVT1 contributes to the pathophysiology of ovarian and breast cancer," Clinical Cancer Research, vol. 13, no. 19, pp. 5745-5755, 2007.

[10] C. I. Brannan, E. C. Dees, R. S. Ingram, and S. M. Tilghman, "The product of the H19 gene may function as an RNA," Molecular and Cellular Biology, vol. 10, no. 1, pp. 28-36, 1990.

[11] L. Wang, Y. Cai, X. Zhao et al., "Down-regulated long noncoding RNA H19 inhibits carcinogenesis of renal cell carcinoma," Neoplasma, vol. 62, no. 3, pp. 412-418, 2015.

[12] I. J. Matouk, N. DeGroot, S. Mezan et al., “The H19 non-coding RNA is essential for human tumor growth," PLoS ONE, vol. 2, no. 9, article e845, 2007.

[13] J.-L. Huang, L. Zheng, Y.-W. Hu, and Q. Wang, "Characteristics of long non-coding RNA and its relation to hepatocellular carcinoma," Carcinogenesis, vol. 35, no. 3, pp. 507-514, 2014.

[14] D. Barsyte-Lovejoy, S. K. Lau, P. C. Boutros et al., "The c-Myc oncogene directly induces the H19 noncoding RNA by allelespecific binding to potentiate tumorigenesis," Cancer Research, vol. 66, no. 10, pp. 5330-5337, 2006.

[15] T. Gao, B. He, Y. Pan et al., "Long non-coding RNA 91H contributes to the occurrence and progression of esophageal squamous cell carcinoma by inhibiting IGF2 expression," Molecular Carcinogenesis, vol. 54, no. 5, pp. 359-367, 2015.

[16] H. Li, B. Yu, J. Li et al., "Overexpression of lncRNA H19 enhances carcinogenesis and metastasis of gastric cancer," Oncotarget, vol. 5, no. 8, pp. 2318-2329, 2014.

[17] N. Berteaux, N. Aptel, G. Cathala et al., "A novel H19 antisense RNA overexpressed in breast cancer contributes to paternal IGF2 expression," Molecular and Cellular Biology, vol. 28, no. 22, pp. 6731-6745, 2008.

[18] S. E. Singletary, C. Allred, P. Ashley et al., "Staging system for breast cancer: revisions for the 6th edition of the AJCC Cancer Staging Manual," The Surgical Clinics of North America, vol. 83, no. 4, pp. 803-819, 2003.

[19] R. DerSimonian and N. Laird, "Meta-analysis in clinical trials," Controlled Clinical Trials, vol. 7, no. 3, pp. 177-188, 1986.

[20] N. Mantel and W. Haenszel, "Statistical aspects of the analysis of data from retrospective studies of disease," Journal of the National Cancer Institute, vol. 22, pp. 719-748, 1959.

[21] E. Zhang, W. Li, D. Yin et al., "c-Myc-regulated long noncoding RNA H19 indicates a poor prognosis and affects cell proliferation in non-small-cell lung cancer," Tumor Biology, vol. 37, article 4007, 2016.

[22] T. Arita, D. Ichikawa, H. Konishi et al., "Circulating long noncoding RNAs in plasma of patients with gastric cancer," Anticancer Research, vol. 33, no. 8, pp. 3185-3193, 2013.

[23] S.-H. Wang, X.-C. Wu, M.-D. Zhang, M.-Z. Weng, D. Zhou, and Z.-W. Quan, "Long noncoding RNA H19 contributes to gallbladder cancer cell proliferation by modulated miR-194-5p targeting AKT2," Tumor Biology, pp. 1-10, 2016. 
[24] L. H. You, Z. J. Liu, and W. De, "Promotive effect of long noncoding RNA H19 on the proliferation of gastric cancer MGC803 cells," Chinese Clinical Oncology, vol. 9, pp. 774-778, 2014.

[25] L. I. C. V. Esteves, A. C. Javaroni, I. N. Nishimoto et al., "DNA methylation in the CTCF-binding site I and the expression pattern of the $\mathrm{H} 19$ gene: does positive expression predict poor prognosis in early stage head and neck carcinomas?" Molecular Carcinogenesis, vol. 44, no. 2, pp. 102-110, 2005.

[26] C. Huang, L. Cao, L. Qiu et al., "Upregulation of H19 promotes invasion and induces epithelial-to-mesenchymal transition in esophageal cancer," Oncology Letters, vol. 10, no. 1, pp. 291-296, 2015.

[27] J. S. Chen, X. Q. Zhang, J. M. Lv, Y. Li, and T. X. X. Liu, "H19 serves as a diagnostic biomarker and up-regulation of H19 expression contributes to poor prognosis in patients with gastric cancer," Neoplasma, vol. 63, no. 2, pp. 223-230, 2016.

[28] Z. Zhu, L. Song, J. He et al., "Ectopic expressed long non-coding RNA H19 contributes to malignant cell behavior of ovarian cancer," International Journal of Clinical and Experimental Pathology, vol. 8, pp. 10082-10091, 2015.

[29] D. Tan, Y. Wu, L. Hu et al., "Long noncoding RNA H19 is upregulated in esophageal squamous cell carcinoma and promotes cell proliferation and metastasis," Diseases of the Esophagus, 2016.

[30] S. H. Wang, X. C. Wu, M. D. Zhang et al., "Upregulation of H19 indicates a poor prognosis in gallbladder carcinoma and promotes epithelial-mesenchymal transition," American Journal of Cancer Research, vol. 6, pp. 15-26, 2016.

[31] D. Han, X. Gao, M. Wang et al., "Long noncoding RNA H19 indicates a poor prognosis of colorectal cancer and promotes tumor growth by recruiting and binding to eIF4A3," Oncotarget, vol. 7, pp. 22159-22173, 2016.

[32] X. Shi, M. Sun, H. Liu, Y. Yao, and Y. Song, "Long non-coding RNAs: a new frontier in the study of human diseases," Cancer Letters, vol. 339, no. 2, pp. 159-166, 2013.

[33] A. M. Khalil and J. L. Rinn, "RNA-protein interactions in human health and disease," Seminars in Cell \& Developmental Biology, vol. 22, no. 4, pp. 359-365, 2011.

[34] A. M. Khalil, M. Guttman, M. Huarte et al., "Many human large intergenic noncoding RNAs associate with chromatinmodifying complexes and affect gene expression," Proceedings of the National Academy of Sciences of the United States of America, vol. 106, no. 28, pp. 11667-11672, 2009.

[35] M. Huarte, M. Guttman, D. Feldser et al., "A large intergenic noncoding RNA induced by p53 mediates global gene repression in the p53 response," Cell, vol. 142, no. 3, pp. 409-419, 2010.

[36] M. Cesana, D. Cacchiarelli, I. Legnini et al., "A long noncoding RNA controls muscle differentiation by functioning as a competing endogenous RNA," Cell, vol. 147, no. 2, pp. 358-369, 2011.

[37] Q. Zhao, T. Li, J. Qi, J. Liu, and C. Qin, "The miR-545/374a cluster encoded in the Ftx lncRNA is overexpressed in HBVrelated hepatocellular carcinoma and promotes tumorigenesis and tumor progression," PLoS ONE, vol. 9, no. 10, Article ID e109782, 2014.

[38] T. Nagano and P. Fraser, "No-nonsense functions for long noncoding RNAs," Cell, vol. 145, no. 2, pp. 178-181, 2011.

[39] L.-L. Chen and G. G. Carmichael, "Decoding the function of nuclear long non-coding RNAs," Current Opinion in Cell Biology, vol. 22, no. 3, pp. 357-364, 2010.

[40] W.-C. Liang, W.-M. Fu, C.-W. Wong et al., “The LncRNA H19 promotes epithelial to mesenchymal transition by functioning as MiRNA sponges in colorectal cancer," Oncotarget, vol. 6, no. 26, pp. 22513-22525, 2015.

[41] L. H. Chan, W. Wang, W. Yeung, Y. Deng, P. Yuan, and K. K. Mak, "Hedgehog signaling induces osteosarcoma development through Yap1 and H19 overexpression," Oncogene, vol. 33, no. 40, pp. 4857-4866, 2014.

[42] S. Li, Z. Yu, S.-S. Chen et al., "The YAP1 oncogene contributes to bladder cancer cell proliferation and migration by regulating the H19 long noncoding RNA," Urologic Oncology: Seminars and Original Investigations, vol. 33, no. 10, pp. 427.el-427.e10, 2015.

[43] M. Luo, Z. Li, W. Wang, Y. Zeng, Z. Liu, and J. Qiu, "Upregulated H19 contributes to bladder cancer cell proliferation by regulating ID2 expression," The FEBS Journal, vol. 280, no. 7, pp. 17091716, 2013.

[44] C. Vennin, N. Spruyt, F. Dahmani et al., "H19 non coding RNA-derived miR-675 enhances tumorigenesis and metastasis of breast cancer cells by downregulating c-Cbl and Cbl-b," Oncotarget, vol. 6, no. 30, pp. 29209-29223, 2015.

[45] C. Ma, K. Nong, H. Zhu et al., "H19 promotes pancreatic cancer metastasis by derepressing let-7's suppression on its target HMGA2-mediated EMT," Tumor Biology, vol. 35, no. 9, pp. 9163-9169, 2014.

[46] E. Raveh, I. J. Matouk, M. Gilon, and A. Hochberg, "The H19 Long non-coding RNA in cancer initiation, progression and metastasis-a proposed unifying theory," Molecular Cancer, vol. 14, no. 1, article 184, 2015.

[47] S. Bandyopadhyay, S. K. Pai, S. C. Gross et al., "The Drg-1 gene suppresses tumor metastasis in prostate cancer," Cancer Research, vol. 63, no. 8, pp. 1731-1736, 2003.

[48] F. Yang, J. Bi, X. Xue et al., "Up-regulated long non-coding RNA H19 contributes to proliferation of gastric cancer cells," The FEBS Journal, vol. 279, no. 17, pp. 3159-3165, 2012.

[49] C. Liu, Z. Chen, J. Fang, A. Xu, W. Zhang, and Z. Wang, "H19derived miR- 675 contributes to bladder cancer cell proliferation by regulating p53 activation," Tumor Biology, vol. 37, article 263, 2016. 


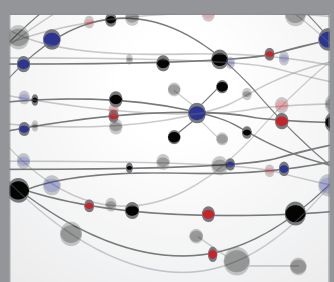

The Scientific World Journal
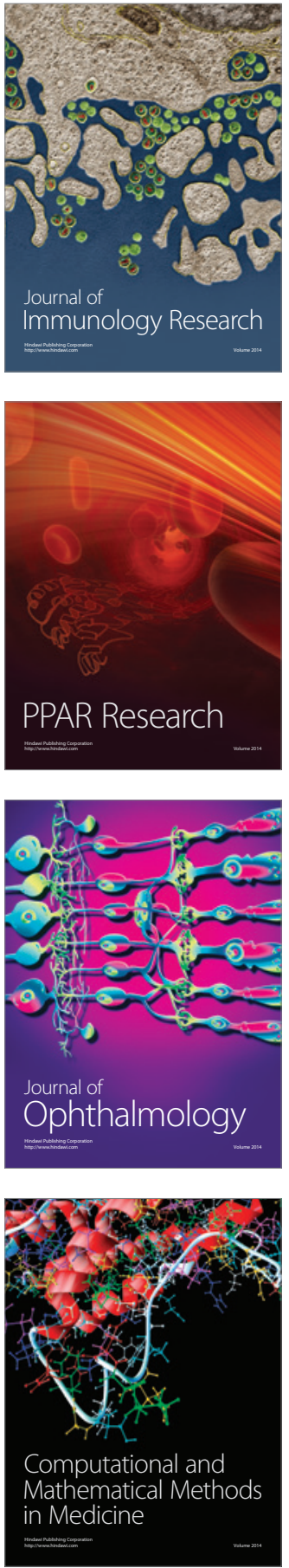

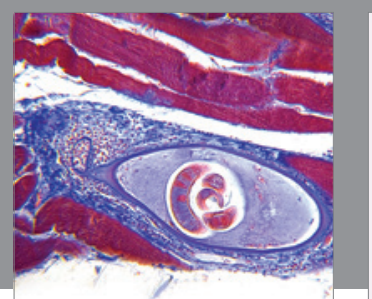

Gastroenterology Research and Practice

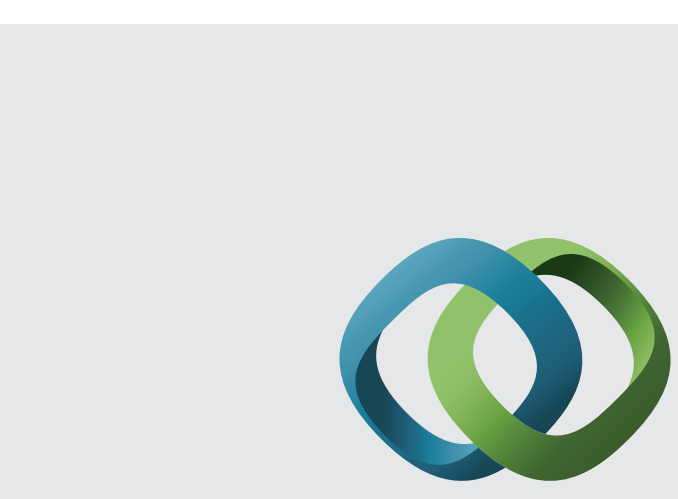

\section{Hindawi}

Submit your manuscripts at

http://www.hindawi.com
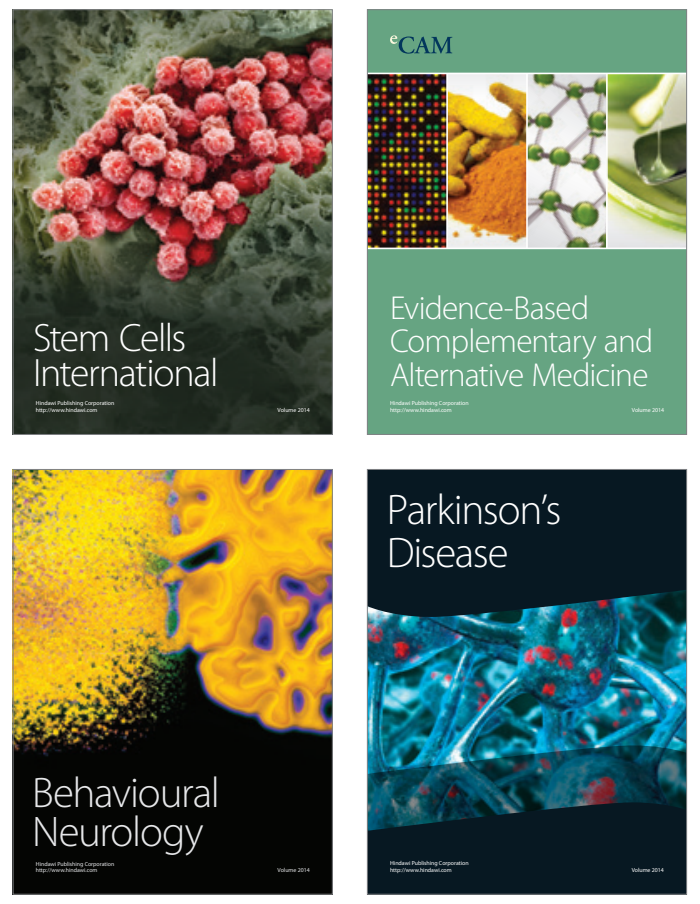
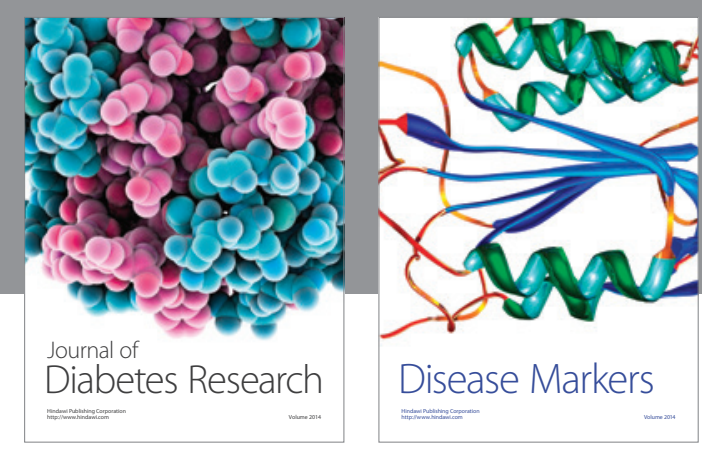

Disease Markers
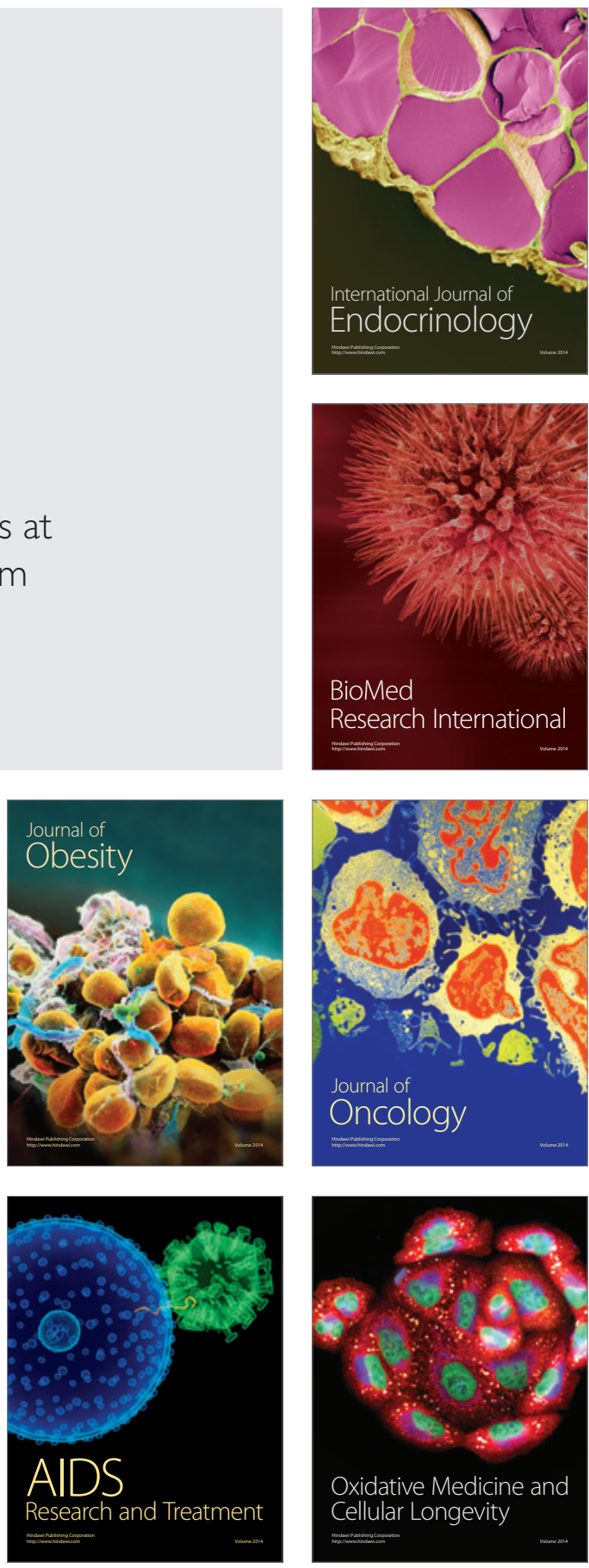